\title{
Dance/Movement Therapy and Developments in Empirical Research: The First 50 Years
}

\author{
Robyn Flaum Cruz ${ }^{1}$
}

Published online: 7 October 2016

(C) American Dance Therapy Association 2016

\begin{abstract}
One of a collection of six scholarly essays solicited by this journal to celebrate the first half-century of the American Dance Therapy Association, this paper describes the centrality of research to the profession since its inception. Using the works of Marian Chace, early conference proceedings, and some brief history about the development of psychotherapy and evidence-based practice as illustrations, this essay presents the historical affiliation between dance/movement therapy and research. The prescience of basic assumptions about dance/movement therapy conceptualized in the early days of the profession, which are now supported by newly emerging neurological and neuropsychological research, is discussed. Among the promising features of the profession noted, are the impressive growth of dance/movement therapy globally, and the fact that the embodied approach embedded in the work has kept the profession close to important body-mind parameters over time. These are argued to ensure its continued growth over the next 50 years. Finally, readers are reminded that engaging with research creates the foundation of improving practice to ultimately benefit clients.
\end{abstract}

Keywords ADTA $\cdot$ Research $\cdot$ Dance/movement therapy research

\section{Dance/Movement Therapy and Developments in Empirical Research}

Dance/movement therapy (DMT) and research have been joined together since the earliest days of the field, but this vital connection has mostly gone unrecognized. Perusal of Marian Chace's early writing clearly shows that the development of what we call DMT followed a path of experimentation, many hours of observation and

Robyn Flaum Cruz

rcruz@lesley.edu

1 Expressive Therapies Program, Lesley University, 29 Everett St., Cambridge, MA 02138, USA 
reflection, and much trial and error (Chaiklin, 1975): the classic characteristics of the early stages of research. The doing, observing, and sensing in one's own body that Chace described as she approached working with non-dancers and then psychiatric patients is still at the core of clinical practice and education in DMT. Even today, dance/movement therapists create embodied hypotheses, which they investigate with clients in an evolving process that bears all the hallmarks of research (Cruz \& Berrol, 2012). As Chaiklin and Chaiklin stated, "Research thinking and practice thinking are identical," (2012, p. 76). One of the earliest print materials on DMT dates to 1945, when Chace published a brief accounting of what she called "classes in rhythmic movement" at St. Elizabeths Hospital in a symposium collection edited by J. L. Moreno (Chace, 1945/1975, p. 52). She described the development of this "experimental" class over a period of 3 years, and documented some of the techniques and considerations that she had devised so far. The close relationship between research and practice that was used to develop and establish the field of DMT is truly embedded in clinical work. While this may seem surprising to many dance/movement therapists who think of research as separate from practice, nevertheless, this relationship is documented not only in Chace's writing, but throughout early American Dance Therapy Association (ADTA) publications.

Context is vital to understanding the past. With respect to DMT and research, it is important to remember that in the 1940s when DMT was getting started, psychotherapy was very young, as was the field of biomedical research, and evidence-based medicine did not yet exist. In the mid-1940s, theoretical formulations made up the biggest focus of attention for proponents of psychotherapy. Different theoretical models were put forward and even Hans Eysenck's 1952 challenge to the efficacy of psychotherapy was based on his adherence to behavior therapy rather than on data, as data were still somewhat rare (Hill \& Corbett, 1993). Also in the 1940s, the National Institute of Health, created through the 1930 Ransdell Act, expanded to an umbrella organization, the National Institutes of Health (NIH), with just over four million dollars in funding by 1947 (NIH, 2016). While initially focused on physical medicine, NIH eventually extended its scope to funding research on psychotherapy and mental illnesses, which contributed to expanding these areas of research. As psychotherapy outcome studies were created in response to Eysenck's challenge, some were in fact funded by NIH. By 1977, Smith and Glass produced the first meta-analysis of psychotherapy outcome research. They wanted to address "questions that had been forming like-does psychotherapy work better than the mere passage of time or the kind attention of another person in alleviating psychological maladjustment or distress? What form of psychotherapy is most efficacious?" (Smith \& Glass, 1983, p. 20).

Around the same time that psychotherapy outcomes were being studied in earnest, the movement that came to be called evidence-based medicine in 1991 (Sur \& Dahm, 2011) was building and also helping create the focus on research that many recognize as so important today. Prior to the movement toward evidencebased medicine, "Clinical practice was historically viewed as the 'art of medicine.' Expert opinion, experience, and authoritarian judgment were the foundation for decision making," (p. 487). The goals of evidence-based medicine were to improve 
clinical and economic outcomes by decreasing variation in practice. Of course, evidence-based medicine spawned both evidence-based practice and evidencebased treatment. "Evidence-based practice is the integration of best research evidence with clinical expertise and patient values," (Institute of Medicine, 2001, p. 147), and evidence-based treatments are typically structured, manualized treatments (Weisz, Jensen-Doss, \& Hawley, 2006). Most dance/movement therapists recognize the product of all of these historical influences in increasing demands of administrators and others since the 1990s for "evidence" that DMT is effective. Further pushed by the proliferation of Health Maintenance Organizations that began to be noticeable in the 1990s (Cruz \& Feder, 2013), accountability now dominates professional practice in all healthcare areas. Outcome research became the major player and research became a reliable, valid, and necessary source of clinical practice knowledge (Sexton, 1999).

Prior to the conflating of these many influences around the 1990s, DMT experienced a developmental growth spurt that was reflected in publications that exhibited a dedicated orientation to research and research thinking. Throughout the 1950s and into the early 1960s, Marian Chace continued to publish accounts and descriptions of DMT that became notably more detailed with respect to existing theories and examples of case material. It is noteworthy that these articles were published across a range of disciplines including psychiatry, social work, nursing, group psychotherapy, and music therapy, to mention just a few. Importantly, publication of her work subjected her formulations and ideas to the critique of others, a feature that is considered a cornerstone of scholarship from the Western scientific viewpoint, and undoubtedly helped push the field further along. These efforts continued and were multiplied once the ADTA was formed, and can be seen in its early conference programs. For example, the Second Proceedings of the ADTA Annual Conference in 1967 contain four papers, a panel discussion, and a workshop. The papers presented by Judith Kestenberg ("Suggestions for Diagnostic and Therapeutic Procedures in Movement Therapy"), Franklin R. Clark ("A Method of Organizing Treatment Programs in Large Psychiatric Hospitals"), Paul Lippman ("Is There Life Before Death? Schizophrenia, Normality, and Other Human Disasters") and Mitchell Dratman ("Reorganization of Psychic Structures in Autism: A Study Using Body Movement Therapy") (ADTA, 1971) illustrate the breadth of this growth and the focus on research, as did the panel and workshop. The panel discussion was titled, "The Necessary Attitudes of the Dance Therapist in the Therapeutic Community," and the panelists were Murry Morgenstern, Marian Chace, Phyllis Lipton, and Judith Umansky. Finally, the workshop was presented by Alma Hawkins and was titled, "Dance Therapy Techniques."

By 1972, just 5 years later, the title of the 7th Annual ADTA Conference, "What is Dance Therapy Really?" illustrates a developmental milestone of reflection that is mirrored in the growth in the conference program, a program that now contained six papers, six video and film presentations, 10 movement workshops, and two panel presentations. The titles represented a great range of considerations-from "Neuromuscular Organization in Emotional States" by Valerie Hunt to "Looking In Reaching Out, Learning to be a Dance Therapist" by Claire Schmais_-and reflected a decided movement toward professionalization (ADTA, 1973). The very 
next year, in 1973, I attended my first ADTA conference and the 8th Annual Conference contained even more (and from my perspective, very exciting) concurrent presentations and keynote talks across the meeting's three and a half days. "Dance Therapist in Dimension: Depth and Diversity" was the conference title (ADTA, 1974). In addition to conference proceedings as key documents of the development, growth, and attention to research in the field, other publications were also produced during these years. Among them, Mason (1974) edited a collection of brief pieces by a large group of dance therapists, Focus in Dance VII: Dance Therapy, and the American Journal of Dance Therapy (AJDT) debuted in March 1977. Research featured prominently in the first AJDT issue, with articles that documented the 1975 annual conference, reporting on research and addressing "Directions for Research in Dance Movement Therapy." A quick review of these articles shows that dance therapists and the field of dance therapy were quite in step with the times. Research on effectiveness of psychotherapy was generally of some interest, as evidenced by the fact that Smith and Glass received the funding for their 1977 meta-analysis of psychotherapy research in 1975 (Smith \& Glass, 1983).

From the perspective of 2016, it is striking that key assumptions originally posed for DMT in the 1970s have current support. One good example of the range of this new support can be found in Koch and Fischman (2011). It is possible that the embodied approach that has been used and taught has kept the key assumptions of DMT close to body-mind parameters that are now reflected in and supported through basic research about how the brain, movement, and relationships function. This research did not exist in the 1970s. In fact, compared to today there was relatively little research on the brain, and research that explored DMT's effectiveness was just getting started. Yet, the more neurophysiology and neuropsychological research that emerges today, the more it is apparent that DMT may become the key to trauma treatment, neurorehabilitation, and other related areas because of how it unifies body and mind. Additionally, there are an increasing number of evidence-based studies on the effects of DMT for various conditions (e.g., Bradt, Goodill, \& Dileo, 2011; Karkou \& Meekums, 2014; Koch, Kunz, Lykou, \& Cruz, 2014), and DMT “can be rightfully called one of the foremost contributors to evidence-based clinical literature on the effectiveness of body-mind interventions," (Cruz \& Koch 2015, p. 11). There are also now solid examples of the several forms of standardized reviews of DMT research, and these reviews highlight one of the most important features of dance therapy in recent years that I have yet to mention.

The exciting globalization of DMT documented in 2005 (Dulicai \& Berger, 2005) has only increased in the last 11 years. Although the impact of that increase on research is difficult to quantify, it is undeniable. There are now Cochrane reviews on DMT in cancer care, schizophrenia, depression, and dementia (Bradt, et al., 2011; Karkou \& Meekums, 2014; Meekums, Karkou, \& Nelson, 2012; Ren \& Xia, 2013). The original meta-analysis of DMT research (Ritter \& Low, 1996) and its correction (Cruz \& Sabers, 1998) were recently supplemented by a meta-analysis of dance and DMT for psychological outcomes (Koch et al., 2014). Taken together, these studies, representing DMT research in many countries, position it well for the future. 
Earlier in this essay, I described how over the decades that DMT has been developing and coming into its own as an international practice and profession, research and accountability in healthcare have come to prominence as well. The focus was on quantitative research and especially the randomized controlled trial (RCT) as the highest of standards. While the status of the RCT has not changed, it is now widely accepted that the RCT and the hypotheses that it is designed to test need to be informed by research using qualitative methods. Indeed, qualitative research is capable of informing theory in ways that quantitative methods cannot: "We must be careful to avoid viewing quantitative and qualitative... as antagonistic," (Cruz \& Feder, 2013, p. 16). The value of qualitative methods that deeply probe the experiences of people to understand "why" and "how" has gained widespread recognition since the 1990s, such that now NIH requires that all projects submitted for funding include quantitative and qualitative components in their design and methods. This wholeness of methods that encompasses group or population effects informed by personal processes and experiences is not far from the norm in DMT, which early on was used primarily with groups of individuals. Given the historical affiliation of DMT clinical practice with research, and the current climate of new respect for body-mind interventions, the future of DMT research is exciting to contemplate.

As the field continues to develop and grow with the help of clinician-researchers and researcher-clinicians in the climate of the 21st century and beyond, I have one caveat to offer. Dance/movement therapists do face challenges of accountability in the systems in which they practice, but they have mounting sources of evidence to support what they do and should use this evidence to inform administrative stakeholders. However, the most important stakeholders for all DMT clinical practices are the people who receive the services. My colleagues and I have argued elsewhere (Cruz \& Berrol, 2012; Cruz \& Koch, 2015) that the real reason for clinicians to engage with published research and their own research practices is to enhance the quality of the services provided. As ADTA begins its next 50 years I hope all dance/movement therapists realize their professional legacy and engage with research for the sake of their clients. Every single client deserves the finest, most informed DMT services we can provide. Let's make sure we give them our best.

Conflict of interest The author declares that she has no conflict of interest.

\section{References}

American Dance Therapy Association. (1967). Monograph No. 1: Writings on body movement and communication; Second annual proceedings (1967). Columbia, MD: American Dance Therapy Association.

American Dance Therapy Association. (1973). What is dance therapy really? Proceedings of the Seventh Annual Conference. Columbia, MD: American Dance Therapy Association.

American Dance Therapy Association. (1974). Dance therapist in dimension: Depth and diversityProceedings of the Eighth Annual Conference. Columbia, MD: American Dance Therapy Association.

Bradt, J., Goodill, S. W., \& Dileo, C. (2011). Dance/movement therapy for improving psychological and physical outcomes in cancer patients. Cochrane Database of Systematic Reviews. doi: 10.1002/14651858.CD007103.pub2. 
Chace, M. (1945/1975). Rhythm in movement as used in St. Elizabeths Hospital. In H. Chaiklin (Ed.), Marian Chace: Her papers (pp. 52-54). Columbia, MD: American Dance Therapy Association. (Reprinted from Group Psychotherapy: A Symposium, pp. 243--45, J. L Moreno (Ed.), New York, NY: Beacon House).

Chaiklin, H. (1975). Marian Chace: Her papers. Columbia, MD: American Dance Therapy Association.

Chaiklin, H., \& Chaiklin, S. (2012). The case study. In R. F. Cruz \& C. F. Berrol (Eds.), Dance/movement therapists in action: A working guide to research options (2nd ed., pp. 75-101). Springfield, IL: Charles C. Thomas.

Cruz, R. F., \& Berrol, C. F. (2012). What does research have to do with it? In R. F. Cruz \& C. F. Berrol (Eds.), Dance/movement therapists in action: A working guide to research options (2nd ed., pp. 12-22). Springfield, IL: Charles C. Thomas.

Cruz, R. F., \& Feder, B. (2013). Feders' the art and science of evaluation in the arts therapies (2nd ed.). Springfield, IL: Charles C. Thomas.

Cruz, R. F., \& Koch, S. (2015). Reading and evaluating quantitative research in body psychotherapy. International Body Psychotherapy Journal: The Art and Science of Somatic Praxis, 14(1), 10-19.

Cruz, R. F., \& Sabers, D. L. (1998). Dance/movement therapy is more effective than previously reported. The Arts in Psychotherapy, 25, 101-104.

Dulicai, D., \& Berger, M. R. (2005). Global dance/movement therapy growth and development. The Arts in Psychotherapy, 32(3), 205-216.

Hill, C. E., \& Corbett, M. M. (1993). A perspective on the history of process and outcome research in counseling psychology. Journal of Counseling Psychology, 40(1), 3-24. doi: 10.1037/0022-0167.40.1.3.

Institute of Medicine. (2001). Institute of Medicine (IOM) crossing the quality chasm: A new health system for the 21st century. Washington, DC: National Academy Press.

Karkou, V., \& Meekums, B. (2014). Dance movement therapy for dementia. Cochrane Database of Systematic Reviews, doi:10.1002/14651858.

Koch, S., \& Fischman, D. (2011). Embodied enactive dance/movement therapy. American Journal of Dance Therapy, 33, 57-72.

Koch, S., Kunz, T., Lykou, S., \& Cruz, R. F. (2014). Effects of dance movement therapy and dance on health-related psychological outcomes: A meta-analysis. The Arts in Psychotherapy, 41(1), 46-64.

Mason, K. C. (Ed.). (1974). Focus on dance vii: Dance therapy. Reston, VA: American Alliance for Health, Physical Education, Recreation, and Dance.

Meekums, B., Karkou, V., \& Nelson, E. A. (2012). Dance movement therapy for depression. Cochrane Database of Systematic Reviews, . doi:10.1002/14651858.

National Institutes of Health. (2016). A short history of the National Institutes of Health by Victoria A. Harden. Retrieved from https://history.nih.gov/exhibits/history/index.html

Ren, J., \& Xia, J. (2013). Dance therapy for schizophrenia. Cochrane Database of Systematic Reviews, . doi: $10.1002 / 14651858$.

Ritter, M., \& Low, K. G. (1996). Effects of dance/movement therapy: A meta-analysis. The Arts in Psychotherapy, 23, 249-260.

Sexton, T. L. (1999). Evidence-based counseling: Implications for counseling practice, preparation, and professionalism. Greensboro, NC: ERIC Clearing House on Counseling and Student Services.

Smith, M., \& Glass, G. (1983). Citation classic meta-analysis of psychotherapy outcome studies. Current Contents/Social \& Behavioral Sciences, 13, 20.

Sur, R. L., \& Dahm, P. (2011). History of evidence-based medicine. Indian Journal of Urology, 27(4), 487-489. doi:10.4103/0970-1591.91438.

Weisz, J. R., Jensen-Doss, A., \& Hawley, K. M. (2006). Evidence-based youth psychotherapies versus usual clinical care: A meta-analysis of direct comparisons. American Psychologist, 61(7), 671.

\section{Robyn Flaum Cruz}

Ph.D., BC-DMT, LPC is Full Professor, Lesley University Expressive Therapies Ph.D. Program. A Past President of American Dance Therapy Association, she is a Board Certified Dance/Movement Therapist with 35 years of experience, Editor-in-Chief Emerita of The Arts in Psychotherapy and of American Journal of Dance Therapy, author of two books on dance/movement therapy, and over 50 scholarly articles across the disciplines of dance/movement therapy, psychology and neurology, and communications disorders and psychology. 